Published in final edited form as:

Int J Drug Policy. 2014 May ; 25(3): 458-464. doi:10.1016/j.drugpo.2013.11.011.

\title{
Income Level and Drug Related Harm among People Who Use Injection Drugs in a Canadian Setting
}

\author{
Cathy Long ${ }^{1,2}$, Kora DeBeck $^{1,3}$, Cindy Feng ${ }^{4}$, Julio Montaner ${ }^{1,5}$, Evan Wood ${ }^{1,5}$, and Thomas \\ Kerr $^{1,5}$ \\ ${ }^{1}$ British Columbia Centre for Excellence in HIV/AIDS \\ ${ }^{2}$ Dalla Lana School of Public Health, University of Toronto \\ ${ }^{3}$ School of Public Policy, Simon Fraser University \\ ${ }^{4}$ School of Public Health, University of Saskatchewan \\ ${ }^{5}$ Department of Medicine, University of British Columbia
}

\section{Abstract}

Background-Higher income is generally associated with better health outcomes; however, among people who inject drugs (IDU) income generation frequently involves activities, such as sex work and drug dealing, which pose significant health risks. Therefore, we sought to examine the relationship between level of income and specific drug use patterns and related health risks.

Methods-This study involved IDU participating in a prospective cohort study in Vancouver, Canada. Monthly income was categorized based on non-fixed quartiles at each follow-up with the lowest level serving as the reference category in generalized linear mixed-effects regression.

Results-Among our sample of 1,032 IDU, the median average monthly income over the study follow-up was $\$ 1050$ [Interquartile range $=785-2000$ ]. In multivariate analysis, the highest income category was significantly associated with sex work (Adjusted Odds Ratio [AOR]=7.65), drug dealing ( $\mathrm{AOR}=5.06$ ), daily heroin injection ( $\mathrm{AOR}=2.97)$, daily cocaine injection ( $\mathrm{AOR}=1.65)$, daily crack smoking ( $\mathrm{AOR}=2.48)$, binge drug use $(\mathrm{AOR}=1.57)$ and unstable housing ( $\mathrm{AOR}=1.67)$. The high income category was negatively associated with being female $(\mathrm{AOR}=0.61)$ and

(C) 2013 Elsevier B.V. All rights reserved.

Send correspondence to: Thomas Kerr, PhD, Director, Urban Health Research Initiative, B.C. Centre for Excellence in HIV/AIDS, University of British Columbia, St. Paul's Hospital, 608-1081 Burrard Street, Vancouver, B.C., V6Z 1Y6, Canada, Tel: (604)806-9116, Fax: (604) 806-9044, urhi-tk@cfenet.ubc.ca.

Authors Contributions: The specific contributions of each author are as follows: CL, KD, CF and TK designed the study and wrote the protocol, CL managed the literature searches and prepared the first draft of the analysis; CF conducted the statistical analyses with input from CL, KD and TK; all authors contributed to the main content and provided critical comments on the final draft. All authors approved the final manuscript.

Competing Interests: Authors declare no other competing interests.

\section{Conflict of Interest}

No conflict declared.

Publisher's Disclaimer: This is a PDF file of an unedited manuscript that has been accepted for publication. As a service to our customers we are providing this early version of the manuscript. The manuscript will undergo copyediting, typesetting, and review of the resulting proof before it is published in its final citable form. Please note that during the production process errors may be discovered which could affect the content, and all legal disclaimers that apply to the journal pertain. 
accessing addiction treatment (AOR=0.64), (all $p<0.05)$. In addition, higher income was strongly associated with higher monthly expenditure on drugs $(>\$ 400)(\mathrm{OR}=97.8)$.

Conclusion-Among IDU in Vancouver, average monthly income levels were low and higher total monthly income was linked to high-risk income generation strategies as well as a range of drug use patterns characteristic of higher intensity addiction and HIV risk. These findings underscore the need for interventions that provide economic empowerment and address high intensity addiction, especially for female IDU.

\section{Keywords}

Canada; Injection drug use; Income generation; Sex work; Drug dealing

\section{INTRODUCTION}

Income is an important determinant of health. It can influence health directly, by its absolute value in shaping material living conditions, and indirectly, by its relative effects on social participation and control over life situations (Marmot, 2002). Individuals who make more income generally experience better health and are better economically positioned to take up health promoting behaviours (Cross et al., 2001; Lynch et al., 2000; Subramanian et al., 2002; Subramanian \& Kawachi, 2004). For example, having a higher income enables better nutrition, exercise, housing, health care, and recreation (Marmot, 2002). Conversely, poverty has a strong deleterious effect on health and is associated with a cornucopia of unhealthy behaviours (Laaksonen et al., 2003; Pfoertner et al., 2011). In particular, low income has been observed to be significantly associated with the consumption of unhealthy goods, such as tobacco, alcohol and illicit drugs (Cerda et al., 2011; Jefferis et al., 2007; Redonnet et al., 2012). Individuals who use illicit drugs are particularly vulnerable to poverty as well as poor health and health behaviours (Ompad et al., 2012). Many frequently experience food insufficiency (Anema et al., 2010), unstable housing and homelessness (Rhoades et al., 2011), physical (Marshall et al., 2008) and sexual (Braitstein et al., 2003) violence, poor mental health (Batki et al., 2010; Topp et al., 2010), blood-borne infections (Aceijas \& Rhodes, 2007; Hagan \& Jarlais, 2000; Miller et al., 2002), and sexually transmitted infections (Celentano et al., 2008; Strathdee \& Sherman, 2003), all of which independently and collectively contribute to worse health.

People who use injection drugs (IDU) often have difficulty achieving financial security and experience significant barriers to legal and meaningful employment. Barriers include employer discrimination (Grover \& Paylor, 2010), having a criminal history (Pager, 2003), mandated drug testing (Tunnel, 2004), unstable housing, and limited education attainment and employable skills (Pinkham et al., 2012; Sherman et al., 2006). In a recent study of employment patterns among a cohort of IDU living in Vancouver, Canada, less than a third reported ever having a regular job and at any point in time only around a tenth report having had a regular job in the previous six months (Richardson et al., 2010). An alternative source of income for many IDU is social assistance (DeBeck et al., 2007); however, provisions from social assistance are often insufficient. A lack of legal employment opportunities leads many IDU to turn to high risk income generating activities, the most common being drug dealing and sex work, both of which carry substantial health risks (Chettier et al., 2010; 
Cross et al., 2001; Shannon et al., 2008; Werb et al., 2008). A strong driver of participation in such activities is the cost of illegal drugs (DeBeck et al., 2007; McCoy et al., 2007; Richardson et al., 2008; Richardson et al., 2010). It has been shown that, IDU with high intensity addiction are both more likely to engage in high-risk income generating activities (DeBeck et al., 2007; Deering et al., 2011) and less likely to have legal employment (Richardson et al., 2010). While involvement in drug dealing or sex work exposes IDU to additional risks of violence, incarceration, and HCV and HIV infection (Epel et al., 2002; Kerr et al., 2008; Werb et al., 2008), when faced with a competition of needs and few alternative income generation opportunities, drug dependence frequently takes precedence and thus lead IDU to resort to risky income generation practices.

Given that people who inject drugs experience a wide range of health risks associated with absolute poverty, it could be expected that greater income would substantially improve their health outcomes and their uptake of health promoting behaviours. However, among IDU the usual benefits conferred by having a higher income may be absent as many IDU rely on risky activities, which carry substantial health risks, for income. To further clarify the role of income in shaping health and health related behaviour among IDU, we sought to examine the relationship between level of income and specific drug use patterns and related health risks. We also sought to examine the relationship between level of income and expenditure on drugs.

\section{METHODS}

The Vancouver Injection Drug User Study (VIDUS) is an open prospective cohort study of individuals who inject illicit drugs, which began enrolment through self-referral and street outreach in May 1996. This cohort has been described in detail previously (DeBeck et al., 2007; Wood et al., 2001). In brief, an individual was eligible if he or she lived in the Greater Vancouver Region District at the time of enrolment, injected illicit drugs in the previous month, and provided written informed consent. At baseline and bi-annually thereafter, participants completed an interviewer-administered questionnaire and provided a blood sample for serologic testing of HIV and HCV. For their time, participants received a stipend of \$20 CDN at each study visit. VIDUS has ethical approval from St. Paul's Hospital and the University of British Columbia's Research Ethics Board.

The current analysis was restricted to active IDU, defined as participants who reported injection drug use in the six months prior to their study visit, who were seen for a study visit during the period of December 11999 and May 31 2005. Measures of key characteristics under investigation are available only over this sample period. All study follow-up visits during the study period that included a report of active injecting drug use in the previous six months were included in the analyses; similarly, all follow-up visits that did not include a report of injecting drugs in the previous six months were excluded from the analyses. Our main outcome of interest, total monthly income, was derived from a single question asking, "what is your current monthly income", which included the following sources of income: social assistance; family and friends; paid work; sex work; drug dealing; criminal activity (e.g., theft, break and entry); and binning and panhandling. Responses for monthly income were categorized into non-fixed quartiles for each follow-up. In addition, participants were 
asked whether they engaged in drug dealing (yes vs. no); sex work, defined as having exchanged sex for money, gifts, food, shelter, clothes, or drugs (yes vs. no); and regular employment, defined as a job or business with regular salary (yes vs. no) in the previous six months. Participants were also asked, "How much do you think you have spent on drugs in the past month?" Responses for monthly expenditure on drugs were divided into two categories at the median (> $\$ 400$ vs. $\$ 400)$.

We also considered socio-demographic and drug use characteristics that have been previously linked to income generation and health. The socio-demographic variables considered were: age (per year older); sex (female vs. male); Aboriginal ancestry (Aboriginal vs. other); and unstable housing, defined as living in a single occupancy hotel, a shelter, a hostel, a treatment or recovery house, or on the street with no fixed address (yes vs. no). The behavioural and drug use variables considered pertained to the previous six months and included: daily heroin injection (yes vs. no), daily cocaine injection (yes vs. no), daily crack smoking (yes vs. no), binge injection drug use defined as a period of time of using injection drugs more than usual (yes vs. no), non-fatal overdose (yes vs. no), receptive syringe sharing defined as borrowing syringes already used by someone else to inject drugs (yes vs. no), and recent engagement in an addiction treatment defined as reporting being enrolled in methadone treatment, a detoxification program, a recovery house, a residential addiction treatment center, or engaging with an addictions counsellor or participating in peer support programs such as Narcotics Anonymous (yes vs. no). We also considered HIV status (yes vs. no), which was determined by a serologic test on the blood sample provided.

In our primary analysis, which sought to determine factors associated with level of monthly income, we used generalized linear mixed-effects models (GLMM), which accounted for within individual similarities across repeated measures over the study period. The lowest level of monthly income served as the reference category. First, we performed bivariate GLMM analyses to calculate the unadjusted odds ratios and $95 \%$ confidence intervals of the associations between variables of interest and level of monthly income. Monthly expenditure on drugs was excluded from the primary analysis because it was expected to be heavily confounded with our measures of high intensity drug use. We then fit a multivariate GLMM to identify factors that were independently associated with level of monthly income. Variables that had an unadjusted odds ratio less than 0.05 were inputted into a multivariate GLMM. Thereafter, we used a backwards model selection based on Type III p-value so that at each step the variable with the highest Type III p-value was dropped until there were no variables with a p-value greater than 0.05 . In sub analysis, we modeled the association between level of monthly income and monthly expenditure on drugs. Unadjusted odds ratios and $95 \%$ confidence intervals were obtained from a bivariate GLMM. All statistical analyses were performed using SAS software version 9.2 (SAS, Cary, NC). All p-values are two sided.

\section{RESULTS}

Between December 11999 and May 31 2005, a total of 1032 active IDU participated in this study, of which $412(40 \%)$ were female and 351 (34\%) identified as being of Aboriginal ancestry. The median age of participants at the start of the sample period was 34 (IQR $=28$ 
$-41)$. The median number of follow-up visits was $5(\mathrm{IQR}=2-9)$. This sample contributed 5158 observations. At December 1999, income quartiles were separated as follows: the 'Lowest' income category ranged from $\$ 0$ to $\$ 697$, the 'Low' category ranged from $\$ 697$ to $\$ 980$, the 'Moderate' category ranged from $\$ 980$ to $\$ 2000$, and the 'High' category ranged from $\$ 2,000$ to $\$ 30,586$. The median monthly income was $\$ 980(\mathrm{IQR}=697-2000)$ at the beginning of the sample period and increased to $\$ 1100$ (IQR $=832-2000$ ) by May 2005 . Characteristics of the study sample at the beginning of the sample period stratified by level of monthly income are presented in Table 1 (as income quartiles were non-fixed over the sample period only data obtained in December 1999 are show in this table). Univariate GLMM analyses of associations between variables of interest and level of monthly income across the entire sample period are presented in Table 2.

In multivariate GLMM analysis (Table 3), level of monthly income was strongly correlated with high risk drug use behaviours and markers of higher intensity drug use in a dosedependent pattern. Relative to the lowest quartile of monthly income, adjusted odds of daily heroin injection, daily cocaine injection, daily crack smoking, and binge drug use increased with increasing level of monthly income. The highest income category was significantly and positively associated with daily heroin injection (Adjusted Odds Ratio $[\mathrm{AOR}]=2.97 ; 95 \%$ Confidence Interval [CI], 0.2.33 - 3.78), daily cocaine injection ( $\mathrm{AOR}=1.65 ; 95 \% \mathrm{CI}, 1.28$ -2.12 ), daily crack smoking ( $\mathrm{AOR}=2.48 ; 95 \% \mathrm{CI}, 1.93-3.17$ ), and binge drug use (AOR $=1.57 ; 95 \% \mathrm{CI}, 1.24-1.99)$. Enrolment in addiction treatment was significantly and negatively associated with the highest level of income (AOR $=0.64 ; 95 \% \mathrm{CI}, 0.05-0.81$ ). In addition, being HIV seropositive was positively associated with all three levels of monthly income, although the adjusted odds of being HIV seropositive decreased from low $(\mathrm{AOR}=3.63 ; 95 \% \mathrm{CI}, 2.82-4.69)$ to moderate $(\mathrm{AOR}=3.28 ; 95 \% \mathrm{CI}, 2.53-4.27)$ to high $(\mathrm{AOR}=1.45 ; 95 \% \mathrm{CI}, 1.05-2.02)$ income. Trends of associations of key variables across income categories in multivariate GLMM analysis are shown in Figure 1.

In addition, level of monthly income was strongly associated with several important sociodemographic characteristics. Older age was significantly and positively associated with low and moderate income. Conversely, being female was strongly and negatively associated with moderate $(\mathrm{AOR}=0.74 ; 95 \% \mathrm{CI}, 0.57-0.97)$ and high $(\mathrm{AOR}=0.61 ; 95 \% \mathrm{CI}, 0.43-0.87)$ income. Unstable housing was significantly and positively associated with the highest category of monthly income ( $\mathrm{AOR}=1.67 ; 95 \% \mathrm{CI}, 1.32-2.12)$. Compared to those who reported the lowest level of income, individuals who reported moderate or high income were significantly and independently more likely to have participated in drug dealing, sex work, and regular employment.

In sub analysis, level of monthly income was strongly associated with monthly expenditure on drugs. At study period baseline, 151 (92\%) participants in the high income category reported a monthly expenditure on drugs above the median (i.e. \$400) while only 98 (64\%), $37(23 \%)$ and $25(16 \%)$ reported spending more than the median in the moderate, low and lowest categories respectively. In bivariate GLMM analysis, the association between level of monthly income and monthly expenditure on drugs increased substantially from low (OR = $2.24 ; 95 \% \mathrm{CI}, 1.79-2.80)$ to moderate $(\mathrm{OR}=10.26 ; 95 \% \mathrm{CI}, 8.19-12.85)$ to high $(\mathrm{OR}=$ 97.77; 95\% CI, $71.49-133.73)$. 


\section{DISCUSSION}

In this study, we examined the relationship between level of income and specific drug use patterns and related health risks. We found that among active IDU living in Vancouver, average monthly income levels were low, much lower than the national before-tax Low Income Cut-Off, which was \$18,051 in 1999 and \$20,344 in 2004 (for a single person family in a city with a population greater than 500,000) (Statistics Canada, 2010). The reported median annual income was $\$ 11,760$ at the start of the study follow-up and only increased to $\$ 13,200$ by 2004 . In adjusted analysis, being female was negatively associated with higher monthly income and individuals who reported higher income were significantly more likely to be unstably housed. Higher monthly income was linked to high-risk income generation strategies and markers of high intensity drug use in a dose-dependent pattern. Additionally, level of income was negatively associated with enrolment in addiction treatment. This study further found that level of income was strongly associated with expenditure on drugs, with odds of reporting an above median expenditure increasing exponentially with increasing income.

That active IDU experience disproportionately high levels of economic disadvantage and poverty has been well documented. Basic needs such as food, shelter and sanitation are frequently unmet (Pfoertner, 2011), all of which increase IDU' susceptibility to poor health. In the present study, levels of unstable housing were high with more than $50 \%$ of the participants in the high income category reporting unstable housing. This finding is consistent with existing research, which documents high levels of unstable housing and homelessness among IDU (Corneil et al., 2006; DeBeck et al., 2011a; Palepu et al., 2010). However, instead of seeing an improvement in housing status with higher income, as is typically the trend in the general population (Marmot, 2002; Robert et al., 2008), odds of unstable housing increased with increasing income. This may reflect the need for IDU with higher intensity addiction to generate more income and to allocate more of their earnings to drug spending. Many studies have noted a positive relationship between unstable housing and high intensity drug use (Cheng et al., 2013; Milburn et al., 2006; Roy et al., 2003). Furthermore, many existing long-term housing options require abstinence from drug use and have rather restrictive regulations, which in addition to Vancouver's exceptionally low rental vacancy rate, pose significant challenges for active IDU to find stable housing (Briggs et al., 2009; Kertesz et al., 2009; Krusi et al., 2010; Palepu et al., 2010). This anomaly hints at the primacy of drug dependence in shaping the economic decisions of IDU and underscores the importance of providing supportive housing options for this population.

In this study, higher income was associated with regular employment, but higher income was more strongly associated with participation in drug dealing and sex work, both of which carry substantial health risks. This finding is in congruence with prior studies, which have noted that many IDU rely on high risk activities to generate income and to support their drug use (Deering et al., 2011; DeBeck et al., 2007). Additionally, being female was positively associated with higher income in bivariate analysis, however, upon adjusting for regular employment, sex work, drug dealing and drug use related practices, being female became negatively associated with higher income. This change in the directionality of the correlation between being female and income level is likely driven by the greater reliance of female 
IDU on sex work for income generation. At baseline, female IDU who reported sex work generated a median monthly income of $\$ 2000$, while female IDU who did not report sex work had a median monthly income of $\$ 811$. This finding echoes previous studies that have found that compared to their male counterparts, female IDU are more likely to rely on high risk income generation activities (DeBeck et al., 2007) and to experience higher unemployment (Richardson et al., 2010; McCoy et al., 2007; Pelissier \& Jones, 2005). This earning disadvantage for female IDU may represent structural barriers that make it more difficult for female IDU to acquire high paying positions in both the legal labour market and shadow economies (Shannon et al., 2008; Pelissier \& Jones, 2005; Grundetjern \& Sandberg, 2012). Overall, these findings add to the empirical evidence supporting the need for interventions that provide economic empowerment, especially for female IDU (Deering et al., 2011; Richardson et al., 2010; DeBeck et al., 2007). If provided with alternative opportunities for income generation that do not demand drug use abstinence, such as lowthreshold employment, many IDU, and in particular sex workers, have expressed a willingness to reduce their involvement in high-risk income generating activities; however, the availability of low-threshold employment is typically scarce (DeBeck et al., 2011b; DeBeck et al., 2007; Deering et al., 2011). Given the low levels of regular employment reported in this study, further development and expansion of feasible and accessible alternative income generation options for people who use injection drugs, such as lowthreshold employment opportunities, should be a public health priority.

As expected, we observed a strong correlation between level of income and markers of high intensity drug use. Prior studies have suggested that increases in income may facilitate increases in drug consumption although patterns of drug use behaviour and intensity will likely vary with source of income. For example, regular employment can provide a potentially stabilizing force for IDU and has been linked to reduced drug use and crime (Magura et al., 2004; Richardson et al., 2010; Richardson et al., 2012). Conversely, receipt of social assistance has been temporally linked to increases in drug consumption, binge drug use, overdose and violence, with the odds of high intensity drug use being significantly higher in the days following social assistance payments (Dobkin \& Puller, 2006; Li et al., 2007; Riddell \& Riddell, 2006). However, there is no indication that receipt of social assistance increases overall drug use above unabated poverty (Rosen, 2011). Participation in drug dealing has been associated with elevated risks of overdose and frequent drug use in addition to violence, HIV infection, and incarceration (Curry \& Latkin, 2003; Latkin, 2002; Semple et al., 2011; Small et al. 2013; Werb et al., 2008). Among female sex workers, the amount of income generated through sex work has been found to be independently correlated with the amount of money spent on drugs and higher income from sex work has been connected to elevated odds of high risk drug use (Deering et al., 2011; Rekart, 2006; Shannon et al., 2008; Spice, 2007). Consequently, the dynamics between high risk income generation and increased and high risk drug consumption may further embed IDU in environments of elevated risk and vulnerability. Given the strong link between high intensity drug use and income generation, the expansion of evidence-based addiction treatment and exploration of innovative addictions treatments is urgently required. Opiate substitution therapies, including methadone maintenance therapy and prescription heroin, have been shown to be highly effective in reducing expenditure on drugs and engagement in risky 
income generation activities (van den Brink et al., 2003; Oviedo-Joekes et al., 2009;

Schwartz et al., 2006). Providing IDU with an alternative source of drugs has the potential to not only reduce the financial burden of drug use but also disengage IDU from drug and sex work markets. Despite evidence supporting the effectiveness of opiate substitution therapies, access and availability to these treatments continues to be a challenge in many setting (Mattick et al., 2009; Smye et al., 2011; Bell et al., 2002). This represents a significant missed opportunity to reduce many of the health and economic harms associated with high intensity drug addiction. Furthermore, to date, substitution and maintenance therapies for stimulant drug users remain illusive. Exploration of innovative addiction treatment therapies in this area is warranted. Supporting innovation in addiction medicine and ensuring that evidence-based addiction treatments are available on demand may be a critical step toward addressing the economic vulnerability of IDU and reducing their engagement in risky income generation activities.

There are several limitations to this study. First, VIDUS is not a random sample and as a consequence, results from this study may not be readily generalizable to other IDU populations. However, there is evidence that this sample is reflective of the Vancouver IDU community from which this cohort was recruited (Tyndall et al., 2001; Wood et al., 2000). Participants were recruited through extensive street-based outreach and "snowball" sampling. Second, keys measures in this study were based on self-report, which are susceptible to recall bias and response bias. For example, income and participation in highrisk activities may have been under-reported. Also, measures of drug dealing and sex work may not account for all informal and non-monetary transactions. Therefore, the significance of drug dealing and sex work in relation to income and high-risk drug use may be underestimated. Furthermore, the present study does not account for the relationship between drug relate harm and income net of expenditure on drugs.

In summary, among our sample of active IDU, average monthly income levels were low. Although higher income is typically beneficial for health, in our study, higher income was associated with high-risk income generation strategies and did not correlate with a number of key markers of economic stability or engagement with health services (e.g. stable housing, enrolment in addiction treatment). These findings underscore the need for more comprehensive social support for this high-risk population. Interventions that provide economic empowerment and address high intensity addiction, especially for female IDU, may help address the paradoxical relationship between income and health risks among IDU and thereby prevent drug related harm.

\section{Acknowledgments}

Role of Funding Sources: The study was supported by the US National Institutes of Health (R01DA011591). This research was undertaken, in part, thanks to funding from the Canada Research Chairs program through a Tier 1 Canada Research Chair in Inner City Medicine, which supports Dr. Evan Wood. Dr. Kora DeBeck is supported by a MSFHR/St. Paul's Hospital-Providence Health Care Career Scholar Award. Dr. Julio Montaner has received an Avant-Garde award (DP1DA026182) from the National Institute of Drug Abuse, US National Institutes of Health. Funding sources had no further role in study design; in the collection, analysis and interpretation of data; in the writing of the report; or in the decision to submit the paper for publication. 
The authors thank the study participants for their contribution to the research, as well as current and past researchers and staff. We would specifically like to thank Cody, Callon, Jennifer Matthews, Deborah Graham, Peter Vann, Steve Kain, Tricia Collingham, and Carmen Rock for their research and administrative assistance.

\section{References}

Aceijas C, Rhodes T. Global estimates of prevalence of HCV infection among injection drug users. International Journal of Drug Policy. 2007; 18:352-8. [PubMed: 17854722]

Anema A, Wood E, Weiser SD, Qi J, Montaner JSG, Kerr T. Hunger and associated harms among injection drug users in an urban Canadian setting. Substance Abuse Treatment, Prevention, and Policy. 2010; 5

Batki SL, Ferrando SJ, Manfredi L, London J, Pattillo J, Delucchi K. Psychiatric disorders, drug use, and medical status in injection drug users with HIV disease. The American Journal on Addictions. 2010; 5(3):249-58.

Bell J, Dru A, Fischer B, Levit S, Sarfraz MA. Substitution therapy for heroin addiction. Substance use \& misuse. 2002; 37(8-10):1149-1178. [PubMed: 12180559]

Braitstein P, Li K, Tyndall M, Spittal P, O’Shanghnessy MV, Schilder A, Johnston C, Hogg RS, Schechter MT. Sexual violence among a cohort of injection drug users. Social Science \& Medicine. 2003; 57(3):561-569. [PubMed: 12791497]

Briggs D, Rhodes T, Marks D, Kimber J, Holloway G, Jones S. Injecting drug use and unstable housing: Scope for structural interventions in harm reduction. Drugs: Education, Prevention, and Policy. 2009; 16(5):436-450.

van den Brink W, Hendriks VM, Blanken P, Koeter MWJ, van Zwieten BJ, van Ree JM. Medical prescription of heroin to treatment resistant heroin addicts: two randomized controlled trials. BMJ. $2003 ; 327$

Celentano DD, Latimore AD, Mehta SH. Variations in sexual risks in drug users: emerging themes in a behavioural context. Current HIV/AIDS Reports. 2008; 5(4):212-8. [PubMed: 18838061]

Cerdá M, Johnson-Lawrence VD, Galea S. Lifetime income patterns and alcohol consumption: Investigating the association between long-and short-term income trajectories and drinking. Social Science \& Medicine. 2011; 73(8):1178-1185. [PubMed: 21890256]

Cheng T, Wood E, Feng C, Mathias S, Montaner J, Kerr T, DeBeck K. Transitions into and out of homelessness among street-involved youth in a Canadian setting. Health \& place. 2013; 23:122127. [PubMed: 23838565]

Chettiar J, Shannon K, Wood E, Zhang R, Kerr T. Survival sex work involvement among streetinvolved youth who use drugs in a Canadian setting. Journal of Public Health. 2010; 32(3):322327. [PubMed: 20061578]

Corneil TA, Kuyper LM, Shoveller J, Hogg RS, Li K, Spittal PM, Schechter MT, Wood E. Unstable housing, associated risk behaviour and increased risk for HIV infection among injection drug users. Health place. 2006; 12:79-85. [PubMed: 16243682]

Cross JC, Johnson BD, Davis WR, Liberty HJ. Supporting the habit: income generation activities of frequent crack users compared with frequent users of other hard drugs. Drug Alcohol Depend. 2001; 64:191-201. [PubMed: 11543989]

Curry MAD, Latkin CA. Gender differences in street economy and social network correlates of arrest among heroin injectors in Baltimore, Maryland. Journal of Urban Health. 2003; 80(3):482-493. [PubMed: 12930885]

DeBeck K, Shannon K, Wood E, Li K, Montaner J, Kerr T. Income generating activities of people who inject drugs. Drug and Alcohol Dependence. 2007; 91:50-6. [PubMed: 17561355]

DeBeck K, Wood E, Zhang R, Buston J, Montaner J, Kerr T. A dose-dependent relationship between exposure to a street-based drug scene and health-related harms among people who use injection drugs. Journal of Urban Health. 2011a; 88(4):724-35. [PubMed: 21533961]

DeBeck K, Wood E, Jiezhi Q, Fu E, McArthur D, Montaner J, Kerr T. Interest in low-threshold employment among people who inject illicit drugs: implications for street disorder. International Journal of Drug Policy. 2011b; 22:376-84. [PubMed: 21684142] 
Deering KN, Shoveller J, Tyndall MW, Montaner JS, Shannon K. The street cost of drugs and drug use patterns: relationships with sex work income in a urban Canadian setting. Drug and Alcohol Dependence. 2011; 118:430-6. [PubMed: 21704461]

Dobkin C, Puller SL. The effects of government transfers on monthly cycles in drug abuse, hospitalization and mortality. Journal of Public Economics. 2007; 91(11):2137-2157.

Epele ME. Gender, violence and HIV: women's survival in the streets. Culture, Medicine and Psychiatry. 2002; 26(1):35-54.

Grover C, Paylor I. No one written off? Welfare, work and problem drug use. Drugs-Education Prevention and Policy. 2010; 17:315-332.

Grundetjern H, Sandberg S. Dealing with a gendered economy: Female drug dealers and street capital. European Journal of Criminology. 2012; 9(6):621-635.

Hagan H, Des Jarlais DC. HIV and HCV infection among injection drug users. The Mount Sinai Journal of Medicine. 2000; 67(5 \& 6):423-8.

Jefferis BJ, Manor O, Power C. Social gradients in binge drinking and abstaining: trends in a cohort of British adults. Journal of epidemiology and community health. 2007; 61(2):150-153. [PubMed: 17234875]

Kerr T, Small W, Johnston C, Li K, Montaner JS, Wood E. Characteristics of injection drug users who participate in drug dealing: implications for drug policy. Journal of Psychoactive Drugs. 2008; 40(2):147-52. [PubMed: 18720663]

Kertesz SG, Crouch K, Milby JB, Cusimano RE, Schumacher JE. Housing first for homeless persons with active addiction: are we overreaching? Milbank Quarterly. 2009; 87(2):495-534. [PubMed: 19523126]

Krüsi A, Fast D, Small W, Wood E, Kerr T. Social and structural barriers to housing among streetinvolved youth who use illicit drugs. Health \& social care in the community. 2010; 18(3):282-288. [PubMed: 20102394]

Latkin CA. Drug users' involvement in the drug economy: implications for harm reduction and HIV prevention programs. Journal of Urban Health. 2002; 79(2):266-277. [PubMed: 12023502]

Li X, Sun H, March DC, Anis AH. Impact of welfare cheque issue days on service for those intoxicated in public. Harm Reduction Journal. 2007; 4:12. [PubMed: 17462093]

Lynch JW, Smith GD, Kaplan GA, Hous JS. Income inequality and mortality: importance to health of individual income, psychosocial environment, or material conditions. British Medical Journal. 2000; 320:1200-4. [PubMed: 10784551]

Magura S, Staines G, Blankertz L, Madison E. The effectiveness of vocational services for substance users in treatment. Substance Use \& Misuse. 2004; 39:2165-2213. [PubMed: 15603001]

Marmot M. The influence of income on health: views of an epidemiologist. Health Affairs. 2002; 21:31-46. [PubMed: 11900185]

Marshall BDL, Fairbairn N, Li K, Wood E, Kerr T. Physical violence among a prospective cohort of injection drug users: a gender-focused approach. Drug and Alcohol Dependence. 2008; 97(3):23746. [PubMed: 18487025]

Mattick RP, Breen C, Kimber J, Davoli M. Methadone maintenance therapy versus no opioid replacement therapy for opioid dependence. Cochrane Database Syst Rev. 2009; 3

McCoy CB, Comerford M, Metsch LR. Employment among chronic drug users at the baseline and 6month follow-up. Substance Use \& Misuse. 2007; 42(7):1055-1067. [PubMed: 17668325]

Milburn NG, Rotheram-Borus MJ, Rice E, Mallet S, Rosenthal D. Cross-national variations in behavioral profiles among homeless youth. American Journal of Community Psychology. 2006; 37(1-2):63-76. [PubMed: 16680537]

Miller CL, Johnston C, Spittal PM, Li K, LaLiberte N, Montaner JSG, Schechter MT. Opportunities for prevention: hepatitis $\mathrm{C}$ prevalence and incidence in a cohort of young injection drug users. Hepatology. 2002; 36(3):737-42. [PubMed: 12198668]

Ompad DC, Nandi V, Cerda M, Crawford D, Galea S, Vlahov D. Beyond income: material resources among drug users in economically-disadvantaged New York City neighborhoods. Drug and Alcohol Dependence. 2012; 120:127-134. [PubMed: 21835561] 
Oviedo-Joekes E, Brissette S, Marsh DC, Lauzon P, Guh D, Anis A, Schechter MT. Diacetylmorphine versus methadone for the treatment of opioid addiction. New England Journal of Medicine. 2009; 361:777-786. [PubMed: 19692689]

Padgett DK, Gulcur L, Tsemberis S. Housing first services for people who are homeless with cooccurring serious mental illness and substance abuse. Research on Social Work Practice. 2006; 16(1):74-83.

Pager D. The mark of a criminal record. American Journal of Sociology. 2003; 108:937-75.

Palepu A, Marshall BDL, Lai C, Wood E, Kerr T. Addiction treatment and stable housing among a cohort of injection drug users. Addiction Treatment \& Housing. 2010; 5:7.

Pelissier B, Jones N. A review of gender differences among substance abusers. Crime \& Delinquency. $2005 ; 51(3): 343-372$.

Rekart ML. Sex-work harm reduction. The Lancet. 2006; 366(9503):2123-2134.

Pfoertner TK, Andress HJ, Janssen D. Income or living standard and health in Germany: different ways of measurement of relative poverty with regard to self-rated health. Int J Public Health. 2011; 56:373-84. [PubMed: 20495993]

Pinkham S, Stoicescu C, Myers B. Developing effective health interventions for women who inject drugs: key areas and recommendations for program development and policy. Advances in Preventive Medicine, 2012. 2012:Article ID 269123.

Redonnet B, Chollet A, Fombonne E, Bowes L, Melchior M. Tobacco, alcohol, cannabis and other illegal drug use among young adults: The socioeconomic context. Drug and alcohol dependence. 2012; 121(3):231-239. [PubMed: 21955362]

Rhoades H, Wenzel SL, Golinelli D, Tucker JS, Kennedy DP, Green HD, Zhou A. The social context of homeless men's substance use. Drug and alcohol dependence. 2011; 118(2):320-325. [PubMed: 21601380]

Richardson L, Wood E, Zhang R, Montaner J, Tyndall M, Kerr T. Employment among users of a medically supervised safer injection facility. The American Journal of Drug and Alcohol Abuse. 2008; 34(5):519-525. [PubMed: 18821450]

Richardson L, Wood E, Li K, Kerr T. Factors associated with employment among a cohort of injection drug users. Drug and Alcohol Review. 2010; 29:293-300. [PubMed: 20565522]

Richardson L, Sherman SG, Kerr T. Employment amongst people who use drugs: A new arena for research and intervention? International Journal of Drug Policy. 2012; 23(1):3-5. [PubMed: 21996164]

Riddell C, Riddell R. Welfare checks, drug consumption, and health: evidence from Vancouver injection drug users. The Journal of Human Resources. 2006; 41(1):138-161.

Robert SA, Booske BC, Rigby E, Rohan AM. Public views on determinants of health, interventions to improve health, and priorities for government. Wisconsin Medical Journal. 2008; 107:124-30. [PubMed: 18575096]

Rosen MI. The 'check effect' reconsidered. Addiction. 2011; 106(6):1071-1077. [PubMed: 21338431]

Roy É, Haley N, Leclerc MP, Cédras ML, Blais L, Boivin JF. Drug injection among street youths in Montreal: predictors of initiation. Journal of Urban Health. 2003; 80(1):92-105. [PubMed: 12612099]

Schwartz RP, Brady JV, Callaman JM. A randomized controlled trial of interim methadone maintenance. Arch Gen Psychiatry. 2006; 63:102-9. [PubMed: 16389204]

Semple SJ, Strathdee SA, Volkmann T, Zians J, Patterson TL. "High on My Own Supply": Correlates of Drug Dealing among Heterosexually Identified Methamphetamine Users. The American Journal on Addictions. 2011; 20(6):516-524. [PubMed: 21999496]

Shannon K, Kerr T, Allinott S, Chettier J, Shoveller J, Tyndall MW. Social and structural violence and power relations in mitigating HIV risk and drug-using women in survival sex work. Soc Sci Med. 2008; 66:911-21. [PubMed: 18155336]

Sherman S, German D, Chen y, Marks M, Bailey-Kloche M. The evaluation of the JEWEL project: an innovative economic enhancement and HVI prevention intervention study targeting drug using women involved in prostitution. AIDS Care. 2006; 18(1):1. [PubMed: 16282070] 
Small W, Maher L, Lawlor J, Wood E, Shannon K, Kerr T. Injection drug users' involvement in drug dealing in the downtown eastside of Vancouver: Social organization and systemic violence. International Journal of Drug Policy. 2013

Smye V, Browne AJ, Varcoe C, Josewski V. Harm reduction, methadone maintenance treatment and the root causes of health and social inequities: An intersectional lens in the Canadian context. Harm Reduction Journal. 2011; 8(1):17. [PubMed: 21718531]

Spice W. Management of sex workers and other high-risk groups. Occupational medicine. 2007; 57(5): 322-328. [PubMed: 17656497]

Statistics Canada. Low income lines 2008-2009. Ottawa, Ontario: Statistics Canada; 2010. (Cat. No. 75F0002M-No.005)Retrieved from: http://www.statcan.gc.ca/pub/75f0002m/75f0002m2010005eng.pdf

Strathdee SA, Sherman SG. The role of sexual transmission of HIV infection among injection and non-injection drug users. Journal of Urban Health. 2003; 80(supplement 3):iii7-14. [PubMed: 14713667]

Subramanian SV, Belli P, Kawachi I. The macroeconomic determinants of health. Annu Rev Public Health. 2002; 23:287-302. [PubMed: 11910064]

Subramanian SV, Kawachi I. Income inequality and health: what have we learned so far? Epidemiologic Reviews. 2004; 26:78-91. [PubMed: 15234949]

Topp L, Hudson SL, Maher L. Mental health symptoms among street-based psychostimulant injectors in Sydney's King's Cross. Substance Use \& Misuse. 2010; 45(7-8):1180-1200. [PubMed: 20441457]

Tunnell, KD. Pissing on demand: Workplace drug testing and the rise of the Detox industry. New York: New York University Press; 2004.

Tyndall MW, Craib KJP, Currie S, Li K, O’Shaughnessy MV, Schechter MT. Impact of HIV infection on mortality in a cohort of injection drug users. JAIDS J Acquired Immune Defic Syndromes. $2001 ; 28: 351$.

Werb D, Kerr T, Li K, Montaner J, Wood E. Risks surrounding drug trade involvement among streetinvolved youth. The American journal of drug and alcohol abuse. 2008; 34(6):810-820. [PubMed: 19016187]

Wood E, Schechter MT, Tyndall MW, Montaner JSG, O'haughnessy MV, Hogg RS. Antiretroviral medication use among injection drug users: two potential futures. AIDS. 2000; 14:1229-35. [PubMed: 10894288]

Wood E, Tyndall MW, Spittal PM, Li K, Kerr T, Hogg RS, Montaner JSG, O’Shaughnessy MV, Schechter MT. Unsafe injection practices in a cohort of injection drug users in Vancouver: could safer injecting rooms help? Canadian Medical Association Journal. 2001; 165(4):405-410. [PubMed: 11531048] 


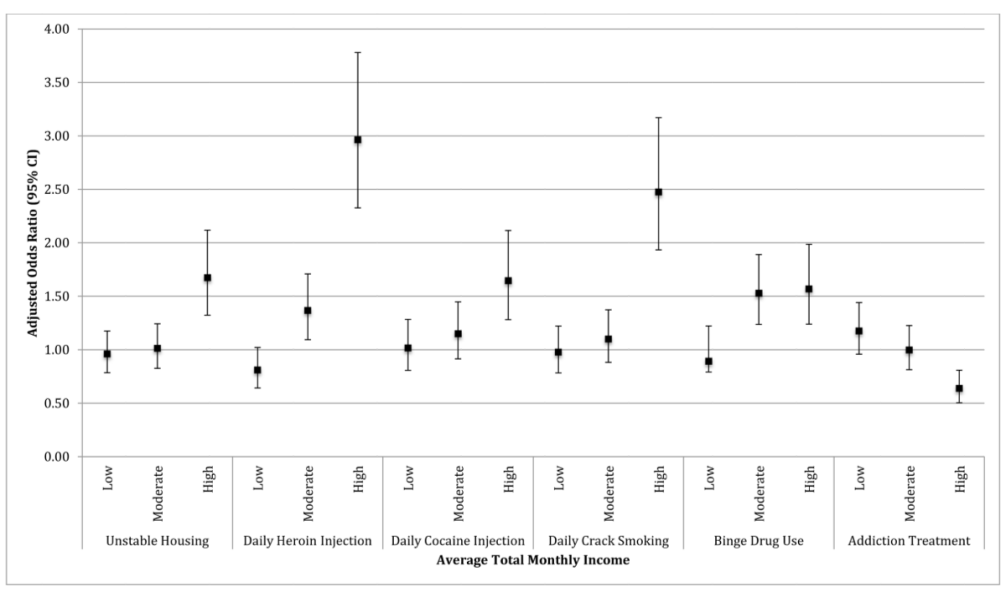

Figure 1. Drug use related factors associated with level of monthly income after accounting for socio-demographic characteristics

The four categories of average total monthly income were defined by non-fixed quartiles for each follow-up. The adjusted odds ratios presented above were derived from a multivariate generalized linear mixed-effects model, which used the lowest category of average total monthly income as the reference category. The model also adjusted for age, female sex, unstable housing in the previous 6 months, engaging in sex work in the previous 6 months, drug dealing in the previous 6 months, regular employment in the previous 6 months and HIV status and included observations from December 11999 to December 302004. 


\section{Table 1}

Characteristics at the start of the sample period (December 1999) stratified by level of monthly income among Vancouver based injection drug users $(n=647)$

\begin{tabular}{|c|c|c|c|c|}
\hline \multirow[b]{2}{*}{ Characteristic } & \multicolumn{4}{|c|}{ Total Monthly Income } \\
\hline & $\begin{array}{c}\text { Lowest } \\
n=161, n(\%)\end{array}$ & $\begin{array}{c}\text { Low } \\
n=162, n(\%)\end{array}$ & $\begin{array}{c}\text { Moderate } \\
n=156, n(\%)\end{array}$ & $\underset{n=168, n(\%)}{\text { High }}$ \\
\hline Median age (IQR) & $38(30-44)$ & $40(35-46)$ & $39(33-45)$ & $34(28-41)$ \\
\hline Female sex & $60(37)$ & $57(35)$ & $58(37)$ & $72(43)$ \\
\hline Aboriginal ancestry & $58(36)$ & $43(27)$ & $51(33)$ & $59(35)$ \\
\hline Unstable housing ${ }^{\dagger}$ & $54(34)$ & $71(44)$ & $67(43)$ & $97(58)$ \\
\hline Sex work ${ }^{\dagger}$ & $9(6)$ & $11(7)$ & $29(19)$ & $56(33)$ \\
\hline Drug dealing ${ }^{\dagger}$ & $10(6)$ & $13(8)$ & $13(8)$ & $25(15)$ \\
\hline Regular employment ${ }^{\dagger}$ & $16(10)$ & $10(6)$ & $22(14)$ & $12(7)$ \\
\hline Daily heroin injection ${ }^{\dagger}$ & $56(35)$ & $33(20)$ & $63(40)$ & $112(67)$ \\
\hline Daily cocaine injection ${ }^{\dagger}$ & $34(21)$ & $26(16)$ & $37(24)$ & $71(42)$ \\
\hline Daily crack smoking ${ }^{\dagger}$ & $41(25)$ & $31(19)$ & $43(28)$ & $77(46)$ \\
\hline Syringe sharing ${ }^{\dagger}$ & $105(65)$ & $119(73)$ & $116(74)$ & $111(66)$ \\
\hline Binge drug use $e^{\dagger}$ & $40(25)$ & $45(28)$ & $57(37)$ & $60(36)$ \\
\hline Non-fatal overdose ${ }^{\dagger}$ & $22(14)$ & $15(9)$ & $16(10)$ & $20(12)$ \\
\hline Addiction treatment ${ }^{\dagger}$ & $87(54)$ & $80(49)$ & $76(49)$ & $57(34)$ \\
\hline HIV positive & $31(19)$ & $76(47)$ & $47(30)$ & $44(26)$ \\
\hline
\end{tabular}




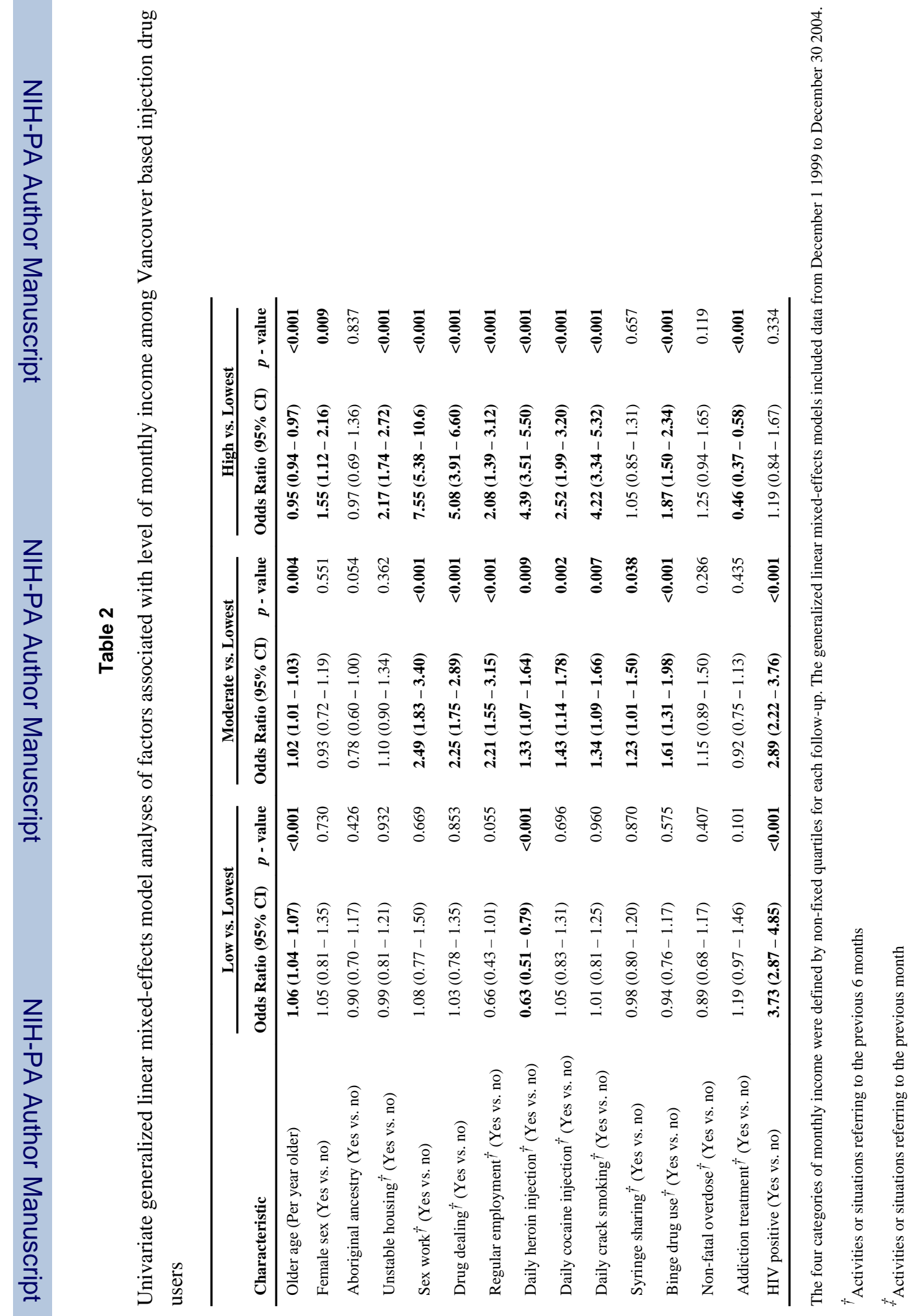




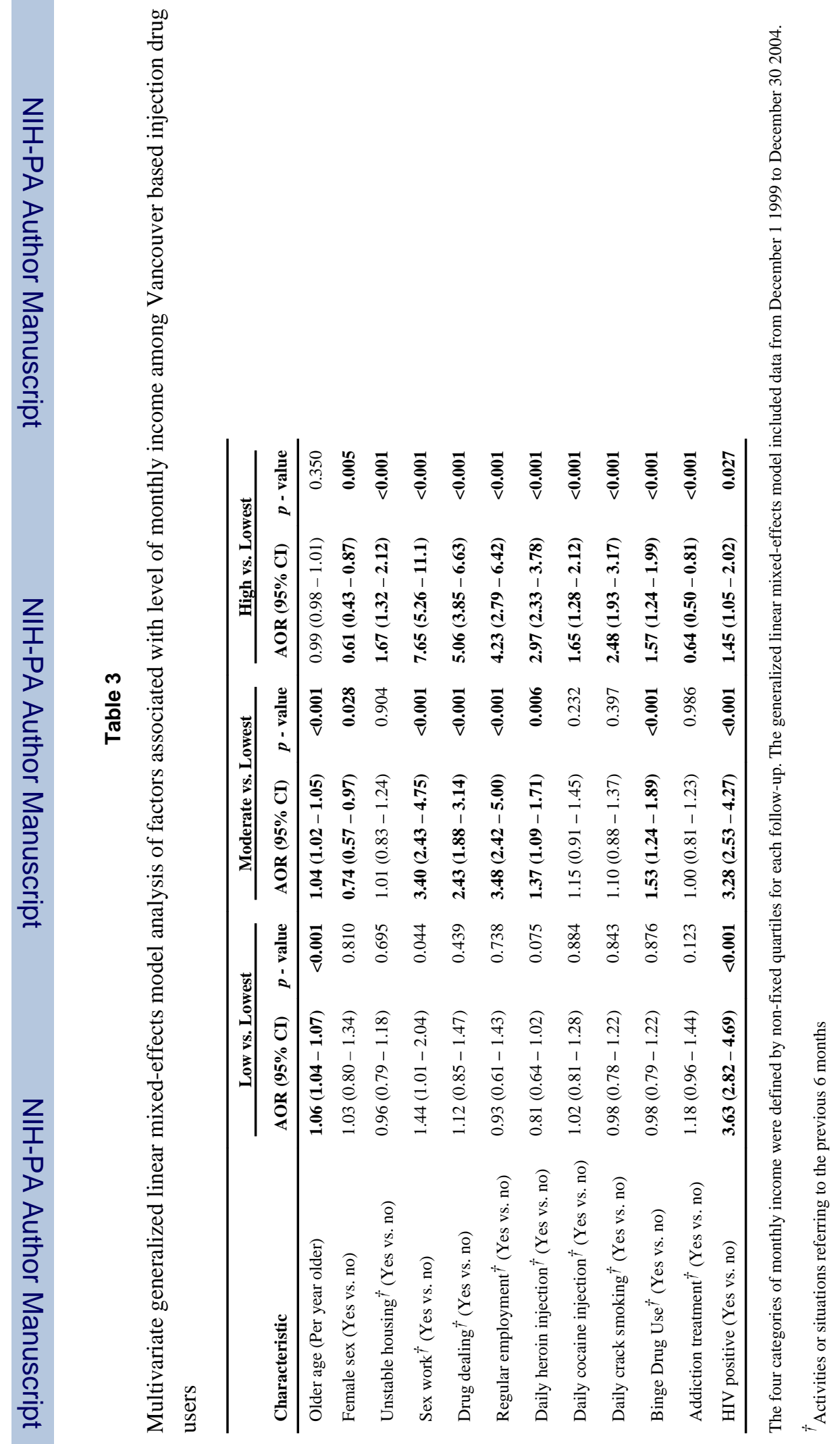

